\title{
Title: Assessment on Constraints and Opportunities of Rice Production Trends in Fogera - Ethiopia. The Case of Lowland Rice Production System
}

\author{
Misganaw Anteneh Tegegne* \\ Associate researcher, Ethiopian Institute of Agricultural Research (EIAR) Agricultural Extension and \\ Communication Research Bahir Dar, Ethiopia
}

*Corresponding Authors: Misganaw Anteneh Tegegne, Associate researcher, Ethiopian Institute of Agricultural Research (EIAR) Agricultural Extension and Communication Research Bahir Dar, Ethiopia.

\begin{abstract}
This study was aiming at assessing on major constraints and opportunities of lowland rice production system in the district of Fogera-Ethiopia. Two peasant associations (Kebeles*) were selected under Fogera district purposively. A total of 80 sample respondents (rice producing farmers) were selected through random method. Both primary and secondary sources of data were assessed under this study. For the data analysis, both descriptive and inferential statistical methods were used. The trends of rice marketing in terms of amounts of supply to the district market has become increasing in both selected peasant associations in the district over the last ten years. However, there are several challenges and constraints in rice production in the study area and at the country level. Insufficient mechanization, market failure of improved varieties, harvest and post-harvest management, traditional means and system of land preparation, availability of biotic stresses (insect pests), weed management, lack of awareness on improved agronomic practices (e.g seed rate) were identified as some of major challenges and constraints of rice production in Fogera-Ethiopia. Concerned governmental and nongovernmental stakeholders must intervene to overcome these challenges and constraints so as to boost rice production and productivity in the study area and the country in general.
\end{abstract}

Keywords: Constraints, Lowland rice, Market, Productivity

\section{INTRODUCTION}

Rice (Oryza sativa L.) is the staple food of over three billion people and plays an important role in the national economy in many developing countries and it is the world's most important food crop of over 50 percent of the world population, particularly of India, China and a number of other countries in Africa and (Ning An et al 2017; Umeh G. N 2015). Ethiopian rice production trends show increases in both area and productivity. Although rice was introduced to the country very recently, it has proven to be a crop that can assure food security in Ethiopia. It is reported that the potential rice production area in Ethiopia is estimated to be about thirty million hectares. Rice has become a commodity of strategic significance across many parts of Ethiopia for domestic consumption as well as export market for economic development. However, Ethiopian rice sector still faces remaining challenges such as high competition with imported rice, poor infrastructure, insufficient mechanization and post-harvest processing technologies, lack of skilled manpower and research facilities, poor marketing infrastructure, and channels (Belayineh et al. 2017; Dawit 2015)

Since 2001, SAA/SG2000 has made significant contributions in introducing rice germplasm and popularizing improved NERICA and Superica-1 varieties in irrigated and rain-fed areas Ethiopia. These areas include central Ethiopian plateaus, settlement areas of Chewaka in Illubabor zone of Oromiya, Guraferda in SNNPR, and irrigated areas of Werer and Gode in Afar and Somali regions, respectively. In line with introduction of varieties, SAA/SG2000 has also given much emphasis to capacity building of researchers, extension workers (Subject Matter Specialists and Development Agents), farmers, private and community seed producers, and private entrepreneurs in post-harvest and agro-processing. Because of all these efforts, rice is recognized as a millennium crop for food security by Ethiopian Government in 2006, and later as a crop, that can contribute to agricultural transformation efforts of the country (Debela et al. 2011). 
Following this Getachew Afework who was initially an expert in South Gondar Department of Agriculture started to collect seed locally from the previous introductions. Initial seeds were therefore obtained from a farmer in Jigna kebele and that was why it was named as X-Jigna. After multiplication, seed was again distributed to other farmers for demonstration and research purposes under his supervision. Following his efforts, Adet Agricultural Research Centre released three other rice varieties called Gumera, Kokit and Tigabe. Adet Agricultural

Now in the district rice is one of the food crops produced by most of the farmers, after maize, teff, and finger millet. In Fogera district its production in hectare has been increasing year after year (CSA, 2013) and Fogera plain contributes about $70 \%$ of rice production in the country (EIAR, 2011). Even though area coverage and volume of production has been increased gradually it is not as such as expected. Its production has still several challenges and constraints.

\subsection{Objectives}

\subsubsection{General Objective}

- To assess major constraints and opportunities of rice production in the lowland rice production system of Fogera -Ethiopia

\subsubsection{Specific Objectives}

- To assess socioeconomic and demographic characteristics of rice producing households

- To assess scenarios of rice marketing over the last ten years

- To assess harvest and post-harvest management practices of small holder rice producing farmers

- To assess agronomic practices of small holder farmers in rice production

\section{Materials ANd Methods}

\subsection{Description of Study Area}

Fogera district is the most potential rice producing area in the country. It was confirmed that $70 \%$ of rice supply has been obtained from this district. There are 33 peasant associations in Fogera district, out of these 10 kebeles are highly potential rice producing areas. Around 21618 hectares of land has been covered by rice production in Fogera. Average altitude of the study area is 1800 meters above sea level. The district is located between the latitudes $11^{\circ} 57$ and $11^{\circ} 59$ and the longitudes $37^{\circ} 42$ and $37^{\circ} 43$. Its mean annual rainfall is $1216 \mathrm{~mm}$ ranging from 1103-1336 presenting a dry season. The district is located within the belt of Lake Tana in North West part of Ethiopia. Moreover, this district is bounded by Erib and Gumara rivers which serve as source of water due to overflow onto Fogera plain. These features of the district could give the opportunity of having high potential in rice production in the country. The rural population is estimated to be around 220000 and the number of agricultural households is approximately 44000 .

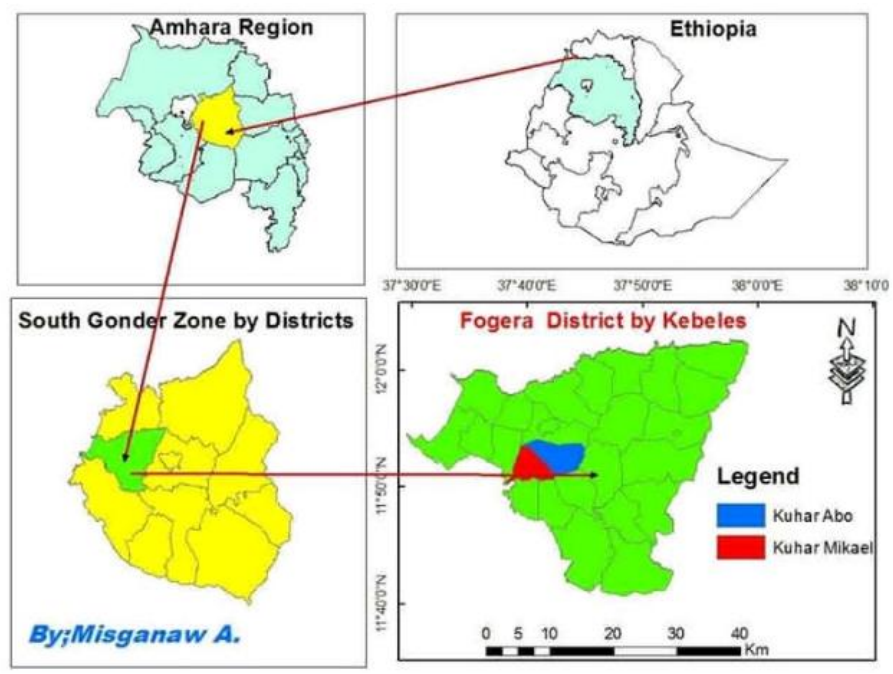




\subsection{Survey Design and Sampling Techniques}

Three stage sampling techniques were applied in this study. First rice producing district was identified in collaboration with agricultural experts and in the second stage two peasant associations (kebeles) were identified in collaboration with development agents. Eventually small holder rice producing households were randomly selected. The sample size was determined using the Slovin's mathematical formula.

$$
\begin{aligned}
& \mathrm{n}=-\frac{\mathrm{N}}{1+\mathrm{N}\left(\mathrm{e}^{2}\right)} \\
& \mathrm{n}=\text { sample size } \\
& \mathrm{N}=\text { target population size } \\
& \mathrm{e}=\text { error margin }
\end{aligned}
$$

\subsection{Data Collection}

Survey tools such as questionnaires and checklists were developed and pre-tested on its appropriateness, fitness, reliability and completeness. Training has been given for data enumerators to have common understanding on the tools developed. In the survey both primary and secondary sources of data were explored. Primary data from respondent smallholder farmers and secondary type of data from different entities such as research centers, district level agricultural and rural development office, NGOs, administrative office in peasant associations, extensions workers, agricultural experts. Besides focused group discussion (FGD) with key informants as supplementary input of the survey were assessed. Qualitative and quantitative types of data were gathered using different data collection techniques.

\subsection{Data Analysis}

Descriptive statistics such as percentage, mean and standard deviation were used to characterize rice producing households and related variables and inferential statistics was applied to analyze variation and statistical significance between groups of variables in both peasant associations. Statistical tools of SPSS and R software were used for both descriptive and inferential statistics

\section{RESULTS AND DISCUSSION}

\subsection{Characterization of Respondents}

Out of 80 respondents assessed in this study, $73(91.3 \%)$ of them were male headed households and $7(8.8 \%)$ female headed households. Regarding to the variety, 60(74.1\%) used local variety and only $5(6.2 \%)$ used improved variety while $15(18.5 \%)$ used both improved and local varieties.

\subsubsection{Age Category of Family Members in the Household}

More than half $(54 \%)$ of total family members in rice producing households were bounded in the age category of fifteen and sixty years' old which is the productive segment of the population and likely involved in agribusiness and rice production. Almost one-fourth (23\%) of total family members were between seven and fourteen years old. From the total family members in the households, $21 \%$ of them are children less than seven years old. This age category consists of young children attending in school not as such engaged in agricultural activities. Family members above sixty-four years old were quit less only consisting of $(2 \%)$.

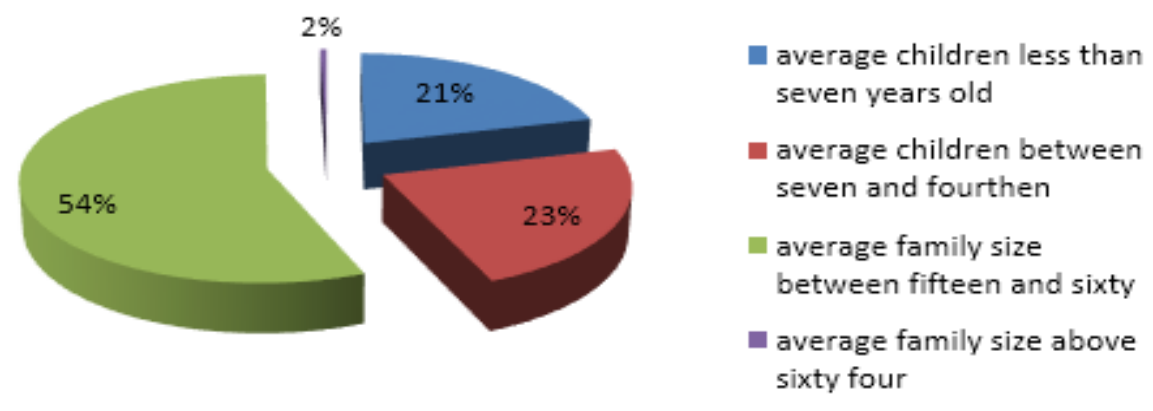

Fig2. Age categories of family members of rice producing households 


\subsection{Rice Marketing Scenarios}

The average sale of rice ten years ago (2008) in Kuhar Abo was 294 kilograms (0.29 tons) per household. On the other hand it was 570.9 kilograms ( 0.57 tons) in Kuar Mikael. Ten years later (2018), the average rice sold per household in Kuar Abo was 1374.3 kilograms (1.37 tons) while 1701 kilograms (1.7 tons) was sold in Kuhar Mikael.

In both timing scenarios (between 2008 and 2018) the average rice grain sold per household in Kuhar Abo has been increased by 1080.3 kilograms or 1.08 tons and in Kuar Mikael rice sale was increased by 1130.1 kilograms or 1.13 tons. Annual increasing rate of rice sale to the district market from Kuar Mikael is higher than Kuar Abo (113kg/year and 108kg/year) respectively. Generally the trend line of rice marketing has increased dramatically over the last one decade in both Peasant Associations. This is due to cumulative effect of increasing area of rice production and productivity, enhancing volume of rice supply at the district market. This indicates rice production goes beyond subsistence based (entirely household consumption) to market oriented or commercial production.

Though all farmers sold rice grain at district market however all of them were not satisfied on the return getting from the market. Market preference of improved variety over local variety was assessed based on the view of farmers. Majority of farmers $62(76.5 \%)$ of them responded that improved varieties had less market acceptance than local ones. This is the association of color quality of grain of improved varieties. Quit few number of farmers $18(22.2 \%)$ contrarily responded that improved varieties had better acceptance at the market. All farmers sold their rice at district market. The share of other market channels such as central market (ECX), village market, and farm gate almost null. Lack of access of central market nearby to residence of farmers contributed to lower return from selling rice.

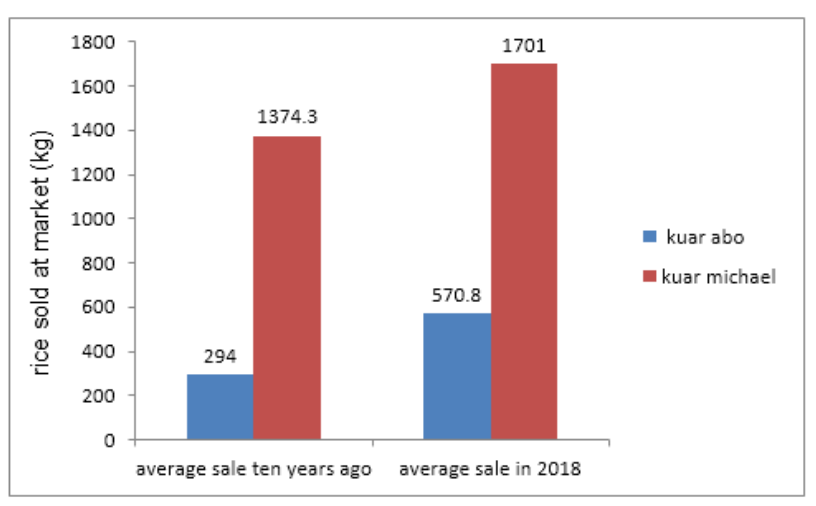

Fig3. Rice marketing between (2008 as baseline and 2018/2019 cropping season)

\subsection{Operations of Land preparation}

Means of land preparation (tillage bunding, and leveling) in rice production in the study area has been undertaken by all farmers using animal plowing. There is no mechanized way like by using tractor machines. This is big drawbacks and shortcomings for smallholder farmers in rice production in Fogera and Ethiopia in general.

\subsection{Seed Rate}

All respondent farmers didn't know the recommended rice seed rate. There is a gap and lack of farmers' awareness on recommended rice seed rate. This urges further training and extension activities to enhance their awareness on the recommended seed rate and among other improved agronomic practices.

\subsection{Biotic stresses (Rice pests and weeds management)}

Weed is one of the challenges for farmers for long time in rice production in Fogera-Ethiopia. All farmers entirely depend on hand weeding. They didn't apply any agro chemicals. Water hyacinth (locally called "Enboch") has become recently one of the challenges and a common invasive weed around areas of belt of Lake Tana where the potential of rice production is relatively higher. Farmers were assessed in this regard whether their rice production is affected by weed of water hyacinth. The result shows water hyacinth is not a problem and never affect in both peasant associations of the study area (Kuhar Mikael and Kuhar Abo), with in the last ten years because of these areas are a little bit of far away from Lake Tana. 
Rice has become affected by different pests and diseases which contribute to lower yielding performance of rice varieties in Fogera-Ethiopia. In this study 56(69.1\%) responded that their cultivated rice varieties were not pest resistant. But 24(29.6\%) of them acknowledged that their varieties were relatively pest resistant. Physical means of pest control was undertaken by $20(24.7 \%)$ farmers and $9(11.1 \%)$ of them applied agro chemical methods. More than half of the respondent farmers $51(63 \%)$ didn't take any measures on pest management.

Termites, According to the assessment of farmers views, the severity level of insect pest (termites) on their rice field was very low for $42(51.9 \%)$ respondent farmers, $5(6.2 \%)$ of them responded the severity level was low, only $2(2.5 \%)$ reported as high, $3(3.7 \%)$ of them was very high and 28(34.6\%) responded termites are highly available on their rice fields.

Weevil is one of insect pests and constraints in rice production; its severity level at storage was assessed in this study. According to the result, 22(27.2\%) of respondents confirmed weevil severity level is very low, 17(21\%) of them reported low, 29(35.8\%) responded high, 7(8.6\%) reported the severity of weevil at storage is very high and just 5(6.2\%) of them reported weevil is not available in their rice storage.

Stem borer is one of the problems in rice production. In this study $27(33.3 \%)$ of the respondents acknowledged that the severity of stem borer on rice field was very low, while 11(13.8\%) of them gave their views on the severity of stem borer is low, 21(25.9\%) of farmers didn't even know about stem borer, $8(9.9 \%)$ high, $10(12.3 \%)$ very high and very few farmers $3(3.7 \%)$ reported that there is no stem borer on their rice farm.

Stacked eye fly is one of the very common insect pests in rice production in Fogera-Ethiopia. An assessment was conducted on farmers in this study regarding this pest. Eighty farmers were assessed in this survey to rank the severity level of stack eye fly on their rice fields in Fogera. The result shows 25( $30.9 \%$ ) of respondents confirmed that its severity level on their rice field is very low, 6(7.4\%) of them reported as low, 6(7.4\%) didn't know about stack eye fly, 36(44.4)\% was high, 6(7.4\%) was very high and only one farmer said there is no any stack eye fly on his rice field. The scenarios of severity level of stack eye fly over the last ten years since 2008 has been increased in the study areas. Ten years ago only $7(8.6 \%)$ farmers reported the severity level of stack eye fly was high but currently $36(44.4 \%)$ of respondents acknowledged that severity level is high in their rice fields (see table 1).

Table1. Severity levels of stack eye fly (pest) on rice fields based on farmers views

\begin{tabular}{|l|l|l|l|l|}
\hline & \multicolumn{2}{|l|}{$\begin{array}{l}\text { Ten years ago } \\
\text { (baseline,2008) }\end{array}$} & \multicolumn{2}{l|}{$\begin{array}{l}\text { Currently } \\
(2018 / 2019)\end{array}$} \\
\hline \multirow{2}{*}{ Severity Level } & Stack eye fly & \multicolumn{2}{l|}{ Stacked eye fly } \\
\cline { 2 - 5 } & frequency & percent & Frequency & Percent \\
\hline Very low & 48 & 59.3 & 25 & 30.9 \\
\hline Low & 17 & 21.3 & 6 & 7.4 \\
\hline Don't know & 6 & 7.4 & 6 & 7.4 \\
\hline high & 7 & 8.6 & 36 & 44.4 \\
\hline Very high & 1 & 1.2 & 6 & 7.4 \\
\hline Not available & 1 & 1.2 & 1 & 1.2 \\
\hline
\end{tabular}

\subsection{Harvest and Post-Harvest Management}

Farmers didn't use harvesting machine with in the last ten years ago between the time interval of (20082018 years). Even they didn't get access and use any harvesting machine since they started rice production in 1970s. This has been a challenge for quit long time for the farmers harvesting rice manually which wastes their time, energy and resources. In-sufficient mechanization has been existed one of the challenges in rice production even at the national level. All farmers in this case assessment use labor for harvesting. The common harvesting time is undertaken in November but sometimes it varies between October and December depending on the varieties (early and late maturity) and among other factors.

Threshing is undertaken using animals by all farmers in the study areas. There is very poor availability and accessibility of threshing machines for the farmers even from the respective bodies of federal government. The mode of rice paddy drying was undertaken using sun radiation energy by all farmers on their fields. This might be the case that in Ethiopia intensity of sun energy is higher all-round the year ("13 months of sun shine") and farmers can take this advantage to dry their rice using sun shine. Unlike Asian countries farmers in Ethiopia didn't use improved drying mechanisms such as constructed 
Title: Assessment on Constraints and Opportunities of Rice Production Trends in Fogera - Ethiopia. The Case of Lowland Rice Production System

pavements or flat beds to save post-harvest loss. Regarding to the management and handling of rice straw after harvesting, 67(82.7\%) of respondents left straw un-burnt on their fields, 3(3.7\%) burnt and the other $10(12.3 \%)$ used it for animal feed.

\subsection{Household and Demographic Characteristics}

The mean age of heads of the households in Kuhar Mikael Kebele was 37 years old and 46 years old in Kuar Abo Kebele. There was statistically significant mean difference of age between the two study areas at $1 \%$ level of significance $(\boldsymbol{p}=\mathbf{0 . 0 0 1}<\mathbf{0 . 0 1})$. The average family size whose age is less than seven was approximately one child per household in both peasant associations and the statistical mean difference between them was not significant. There was statistical mean difference at $1 \%$ level of significance on the family size whose age is between seven and fourteen in two peasant associations $(p=0.01<0.05)$. The mean family size whose age is between fifteen and sixty four was nearly three in both peasant associations per household. It is statistically insignificant. $(\mathbf{p}=\mathbf{0 . 7 9 6}>\mathbf{0 . 0 5})$, see table 2 .

Table2. Households and Demographic Characteristics

\begin{tabular}{|l|l|l|l|l|l|}
\hline & Kuar Mikael (PA*) & \multicolumn{2}{l|}{ Kuar Abo (PA*) } & P-value \\
\hline Variables & Mean & S.D & Mean & S.D & \\
\hline Age of head of household (years) & 37 & 11.56 & 46 & 11.59 & $\mathbf{0 . 0 0 1 * * *}$ \\
\hline Family size whose age is less ( 7 ) & 1.025 & 0.83 & 1.20 & 0.88 & 0.364 \\
\hline Family size whose age is between (7-14) & 0.85 & 0.921 & 1.58 & 0.931 & $\mathbf{0 . 0 1 * * *}$ \\
\hline Family size between (15-64) & 2.96 & 1.021 & 3 & 1.519 & 0.796 \\
\hline family size whose age is above (> 64) & 0.0 & 0.0 & 0.05 & 0.221 & 0.156 \\
\hline
\end{tabular}

$* * *=$ statistically significant at $1 \%$ level of significance and $* *=$ statistically significant at $5 \%$

*Peasant Association or local name is "Kebele" which is a decentralized unit of administration

\subsection{Socioeconomic Characteristics}

Tropical Livestock Unit has been used as conversion factor to estimate the mean of livestock asset in rice producing households. Livestock is an important asset for farmers as source of food, cash and among other things. The average livestock assets (cattle, sheep, goat and chicken) were almost approximate in both peasant associations and there were no statistically significant mean variation on the ownership of cattle, sheep, goat and chicken by rice producing households between the two areas (see table 3).

Table3. Livestock Assets of the Households

\begin{tabular}{|l|l|l|l|l|l|l|}
\hline & & \multicolumn{2}{l|}{ Kuar Mikael } & \multicolumn{2}{l|}{ Kuar Abo } & P-value \\
\hline Variables & $\begin{array}{l}\text { Conversion } \\
\text { factor (TLU) }\end{array}$ & Mean & S.D & Mean & S.D & \\
\hline Livestock asset (cattle) in TLU & 0.7 & 3.48 & 2.98 & 3.43 & 2.99 & 0.91 \\
\hline Livestock asset (sheep) in TLU & 0.1 & 0.09 & 3.32 & 0.10 & 3.67 & 0.899 \\
\hline Livestock asset (goat) in TLU & 0.1 & 0.08 & 1.11 & 0.0 & 0.0 & 0.32 \\
\hline Livestock asset (chicken) in TLU & 0.01 & 0.04 & 6.04 & 0.07 & 8.31 & 0.101 \\
\hline
\end{tabular}

$* * *=$ statistically significant at $1 \%$ level of significance and $* *=$ statistically significant at $5 \%$

The mean variation of amounts of rice sale between two peasant associations was not statistically significant in 2018 and 2019 cropping season $(\mathbf{p = 0 . 5 0 6 > 0 . 0 5})$. However, the mean difference of rice grain sold ten years back at district market between two Peasant associations was statistically significant at $5 \%$ level of significance $(\boldsymbol{p}=\mathbf{0 . 0 3 7}<0.05)$

Table4. Rice marketing

\begin{tabular}{|l|l|l|l|l|l|}
\hline & \multicolumn{2}{|l|}{ Kuar Mikael } & \multicolumn{2}{l|}{ Kuar Abo } & P-value \\
\hline Variables & Mean & S.D & Mean & S.D & \\
\hline Rice grain sold in 2018 $(\mathrm{kg})$ & 1701 & 1845.2 & 1374 & 2481.1 & 0.506 \\
\hline $\begin{array}{l}\text { Rice sold ten years ago } \\
\text { (baseline, 2008) }\end{array}$ & 571 & 731.1 & 294 & 383.5 & $\mathbf{0 . 0 3 7 * *}$ \\
\hline
\end{tabular}

${ }^{* * *}=$ statistically significant at $1 \%$ level of significance and ${ }^{* *}=$ statistically significant at $5 \%$

\section{CONCLUSION AND RECOMMENDATION}

There are several challenges and constraints in the study area and the country in rice production as reported in this study and others. Insufficient mechanization, market failure of improved varieties, lack 
of improved harvest and post-harvest managements, traditional means of land preparation, rice pests and weed management, lack of awareness on improved agronomic practices (eg seed rate) were identified as major challenges and constraints of rice production in Fogera-Ethiopia. Research institutions, governmental and non-governmental stakeholders need to take into consideration in the planning of policies, strategies and research intervention to overcome these challenges and constraints so as to boost rice production and productivity in the study area and the country in general. If these production challenges will be addressed the country will also ensure food security as rice was already considered as strategic and millennium crop so far.

\section{REFERENCES}

[1] Belayineh Tamirat., Jember Tekle., 2017. Review on adoption, trend, potential, and constraints of rice production to livelihood in Ethiopia. International Journal of Research - Granthaalayah, 5(6), 644-658. https://doi.org/10.5281/zenodo.824116.

[2] Dawit Alemu., 2015. Rice in Ethiopia: Progress in Production Increase and Success Factors. 6th CARD General Meeting, Novermbert, 2015

[3] Debela Abera., Zewudie G/Tsadik., 2011. Experiences of SAA/SG 2000 in Rice Technology Transfer SASAKAWA GLOBAL 2000, (SAA/SG2000). Challenges and Opportunities of Rice in Ethiopian Agricultural Development

[4] Ning An., Wenliang Weia., Lei Qiaoa., Fusuo Zhanga., Peter Christiea., Rongfeng Jianga., Achim Dobermannc., Keith W.T., Gouldingc., Jinglong Fand., Mingsheng Fana., 2017. Agronomic and environmental causes of yield and nitrogen use efficiency gaps in Chinese rice farming systems. European Journal of Agronomy. Journal homepage: www.elsevier.com/locate/eja

[5] Ray Lamitin (1999): Rice Post-harvest Operations (international Rice Research Institute),

[6] Umeh G. N., 2015. Determinants of Adoption of Improved Rice Production Technologies in Ebonyi State of Nigeria. Journal of Biology, Agriculture and Healthcare. ISSN 2224-3208 (Paper. ISSN 2225-093X (Online) Vol.5, No.7, 2015

Citation: Misganaw Anteneh Tegegne, "Title: Assessment on Constraints and Opportunities of Rice Production Trends in Fogera - Ethiopia. The Case of Lowland Rice Production System", International Journal of Research Studies in Agricultural Sciences (IJRSAS), vol. 6, no. 4, pp.1-7, 2020. Available: DOI: http://dx.doi.org/10.20431/2454-6224.0604001

Copyright: (C) 2020 Authors. This is an open-access article distributed under the terms of the Creative Commons Attribution License, which permits unrestricted use, distribution, and reproduction in any medium, provided the original author and source are credited. 